\title{
Tuning into the mind
}

Musicophilia: Tales of Music and the Brain Oliver Sacks MD

Alfred A. Knopf; 2007

$381 \mathrm{pp} \$ 34.95$ ISBN 978-0-676-97978-7

$\mathrm{N}$ eurologist Oliver Sacks' great gift, as seen in a number of engaging volumes such as The Man Who Mistook his Wife for a Hat and Awakenings, is to draw on the startling and extraordinary stories of individuals suffering from aberrations in neurologic function, and to use these narratives to work backwards toward understanding their pathology. Beginning with the premise (argued with much support) that music, like language, is a central element of what makes us human, his object in Musicophilia: Tales of Music and the Brain is to comprehend the neurological basis of music.

An amateur musician himself, Sacks unites personal and family stories with those of patients and other correspondents from over the years to investigate how both the pathological and normal may lie on a continuum. The range of what he studies goes from severe musical hallucinations, at one end, to the phenomenon of perfect pitch; from musicogenic epilepsy to catchy tunes we can't get out of our heads.

His selection of stories (and there are many) is aimed at showing that things that we think should be linked on have, in fact, different neural representation. Some individuals can understand rhythm but not melody, and vice versa; some who cannot speak can respond to music. Some, who, because of accident or disease, have no memory can nevertheless play or sing or

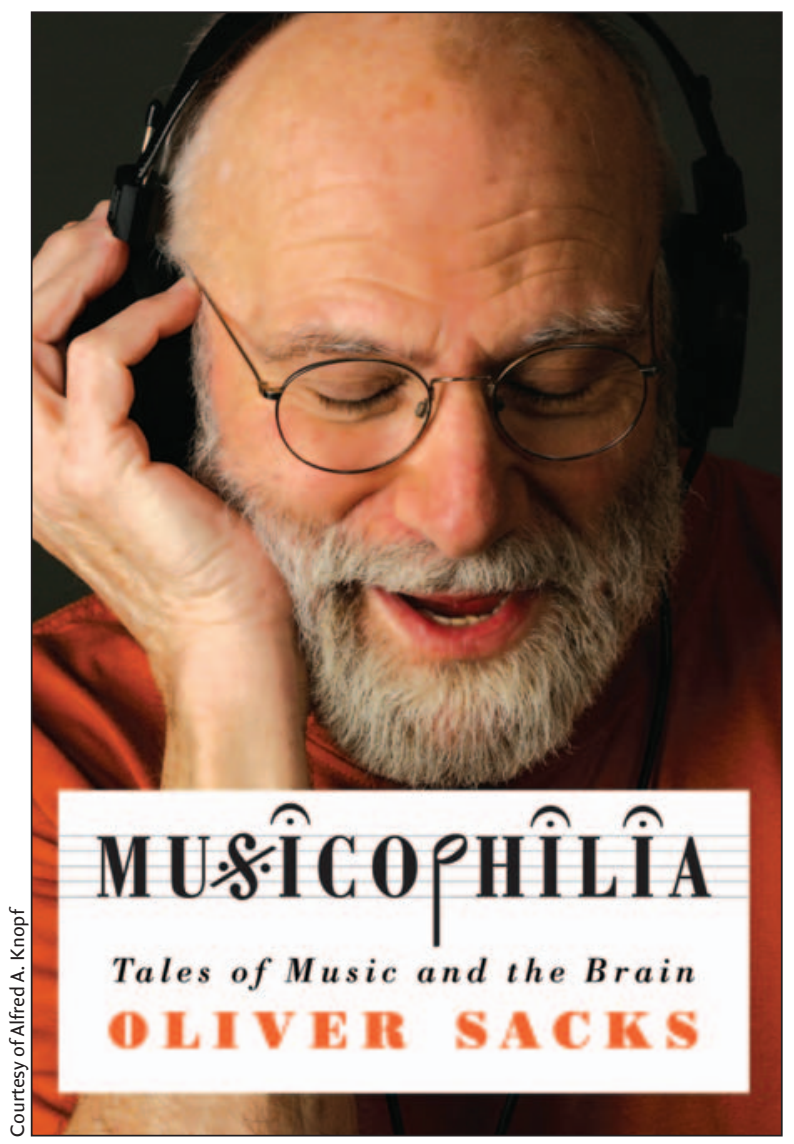

Who Mistook his Wife for a Hat, Dr. S sings that neurology has many words for every neural or mental function of which patients are derived words for everything they are not, but not for what they really are.

Sacks' driving curiosity to understand the story of illness within the entire context of a person's life - in other words, the medical and the human dimensions - is what makes his work of particular interest to physicians. The bonus is that his stories also contain positive medical lessons about human musicality. (For instance, music therapy has proved successful in helping patients with everything from parkinsonian immobility to Alzheimer dementia.)

even compose music. In each chapter, Sacks tells us the story of a person, moves to the neurological discussion, and then on to the newest concepts of neuroscience and imaging techniques that have actually allowed us to watch the brain function.

Sacks cites one of his many correspondents, psychoanalyst Leo Rangell, who wrote in a newspaper article that he considered himself a kind of living laboratory, an experiment in nature through an auditory prism. Each of the book's many protagonists is this kind of living laboratory for Sacks as well. In the opera version of The Man
This book allows us to stand in wonder, alongside Sacks, at the human brain - this time in conjunction with music, something many physicians hold dear.

\section{Linda Hutcheon PhD}

Professor of English and Comparative Literature

University of Toronto

Michael Hutcheon MD

Deputy Physician-in-chief

for Education

University Health Network

University of Toronto

Toronto, Ont. 